\title{
Magnesium Sulfate Poisoning Revealed by Hypothermia and Visual Disturbances: About a Case
}

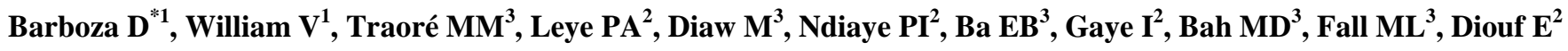 \\ ${ }^{1}$ Department of Anaesthesiology and Resuscitation, Peace Hospital, Health Sciences Faculty, University Assane Seck \\ Ziguinchor Senegal \\ ${ }^{2}$ Department of Anaesthesiology and Resuscitation, Aristide Le Dantec Hospital, Faculty of Medicine, Cheikh \\ Anta Diop University, Dakar Sénégal \\ ${ }^{3}$ Department of Anaesthesiology and Resuscitation, Fann Hospital, Faculty of Medicine, Cheikh Anta Diop University, \\ Dakar Sénégal \\ ${ }^{4}$ Department of Urology and Andrology, Aristide Le Dantec Hospital, Faculty of Medicine, Cheikh Anta Diop University, \\ Dakar Sénégal
}

\section{*Corresponding author -}

\section{Denis Barboza}

Peace Hospital, Ziguinchor Senegal. Email - denisbarboza7@ gmail.com

\begin{abstract}
Eclampsia requires appropriate treatment of pregnancy-induced hypertension and early management before the onset of signs of seriousness. Patients in post-caesarean section are transferred to intensive care. Magnesium sulfate is the drug of choice because it reduces the incidence of eclampsia attacks in severe pre-eclamptic patients and the risk of recurrent seizures in eclamptic patients. Like any medicine, it has side effects, some of which may go unnoticed. This is a 30-year-old primip female patient at the maternity hospital for severe pre-eclampsia. Blood pressure was $180 / 130 \mathrm{mmHg}$. The patient had severe vertigo and edema. She was put under magnesium sulfate $(\mathrm{MgSO} 4)$ at a rate of $4 \mathrm{~g}$ in $20 \mathrm{minutes}$ then $1 \mathrm{~g} / \mathrm{h}$ in pre and post-caesarean section. At the twelfth hour after admission to intensive care, she presented visual blur and persistent hypothermia. The course of action consisted in stopping magnesium sulfate and administering $2 \mathrm{~g}$ of calcium gluconate. The evolution was favorable with a return to normal temperature and a good quality vision. The electrocardiogram was normal. She was transferred to the maternity ward at day 6 .
\end{abstract}

Keywords: Magnesium sulphate-Eclampsia-Intoxication-Calcium gluconate.

\section{Background}

Eclampsia, a serious complication of pre-eclampsia, is a relatively common pathology in our developing countries. It requires appropriate treatment of pregnancy-induced hypertension and early management before the onset of signs of seriousness. ${ }^{[1]}$ Magnesium, in the form of magnesium sulfate (MgSO4), has long been used by anesthetists and obstetricians, empirically, during the eclampsia crisis. The management is multidisciplinary; postcaesarean section patients must be transferred to intensive care. Magnesium sulfate reduces the incidence of eclamptic seizures in severe pre-eclamptic patients and the risk of seizure recurrence in eclamptic patients. ${ }^{[2,3]}$ It has been used in obstetrical practice for decades for its neuroprotective effect. Magnesium poisoning is uncommon. In high doses, its toxicity is mainly cardiac and neuromuscular. We report the case of intoxication revealed by persistent hypothermia associated with visual disturbances.

\section{Patient and Observation}

This is a 30-year-old female primip patient with no previous history of severe pre-eclampsia received at the maternity ward. At admission, the weight was $63 \mathrm{~kg}$ and the blood pressure was 180/130 $\mathrm{mmHg}$. The patient had severe vertigo and edema. She was put under magnesium sulfate $(\mathrm{MgSO} 4)$ at a rate of $4 \mathrm{~g}$ in 20 minutes then $1 \mathrm{~g} / \mathrm{h}$ and the indication of a caesarean was requested. At the pre-anesthetic visit, we found a very good general condition, a heart rate at $117 \mathrm{~b} / \mathrm{min}$, a blood pressure of $160 / 110$ $\mathrm{mmHg}$. The hemoglobin level was $12.2 \mathrm{~g} / \mathrm{dl}$ and the platelets 175,000 elements / mm3. She was considered fit for spinal anesthesia. At the end of the intervention, she was transferred to the resuscitation for the continuation of the care. At admission, we found a patient in good condition. A pitting edema was present. Biologically, renal function, blood composition and liver function returned normal. Treatment initiated with resuscitation was magnesium sulfate $1 \mathrm{~g} / \mathrm{h}$ at the push of the syringe, tramadol $400 \mathrm{mg} / 24 \mathrm{~h}$, nicardipine $50 \mathrm{mg}$ orally twice a day, injectable ketoprofen 100mg twice a day and paracetamol $1 \mathrm{~g}$ four times a day. Twelve hours after admission and magnesium sulfate, the patient experienced persistent hypothermia at 33-34 ${ }^{\circ} \mathrm{C}$ despite heating and blurred vision. There was mild adynamia and 


\section{International Journal of Innovative Research in Medical Science (IJIRMS) Volume 03 Issue 09 Sept. 2018, ISSN: 2455-8737, Imp. Factor - 4.102 \\ Available online at $-\underline{w w w . i j i r m s . i n}$}

osteotendinous reflexes were normal. Blood pressure, heart rate, and respiratory rate were normal. The course of action consisted in stopping the magnesium sulfate, then administering 2 ampoules of calcium gluconate and performing an electrocardiogram (Figure 1) that was normal.

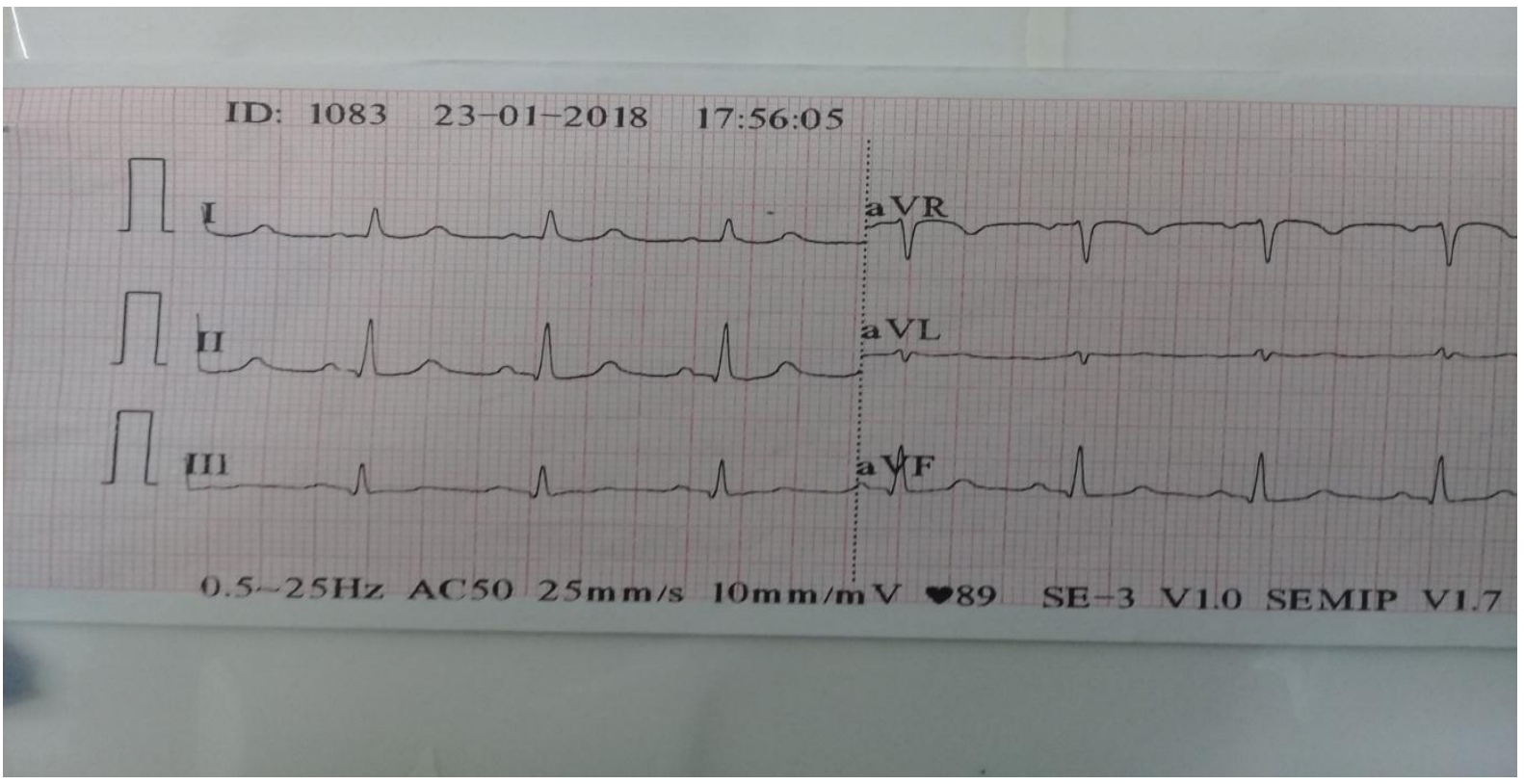

Figure 1: Electrocardiogram after magnesium sulfate poisoning

The evolution was favorable, marked by a rise in temperature to $37.2^{\circ} \mathrm{C}$, a clear vision and a resumption of physical activity. Ketoprofen was discontinued on D3 and the patient was switched to oral relay (paracetamol and nicardipine). She is transferred to the maternity ward on the sixth day of her hospitalization.

\section{Discussion}

Magnesium sulfate has been used for more than 50 years to tocolytic aim and to prevent the eclampsia crisis. In the United States, it has long been regarded as first-line tocolytic therapy. ${ }^{[4]} \mathrm{In}$ our developing countries, magnesium sulfate is at the center of treatment for severe pre-eclampsia and eclampsia. It is an effective and cheaper product. Many studies confirm its use in obstetrics and obstetric resuscitation in Africa. ${ }^{[5,6,7]}$ Magnesium salts are widely used in obstetrics in pregnancy-induced hypertension, preeclampsia, and eclampsia. This treatment has been proposed intrathecally since 1906 , then by the venous route from $1925{ }^{[8]}$ In cases of severe pre-eclampsia and especially when there are prodromes present, $\mathrm{MgSO} 4$ reduces the risk of eclampsia, with greater efficacy than conventional anticonvulsants. In this particular case, their neurological protective character seems particularly interesting. ${ }^{[9]}$ A low dose protocol reduces the risk of maternal hypermagnesaemia and fetal side effects. It should be noted that magnesium sulfate has side effects, most often minor. However the serious toxicity, even if it remains exceptional with a suitable monitoring, remains possible. Thus rare cases of severe accidents with maternal death by overdose have been reported. ${ }^{[10]}$ justifying rigorous recommendations in surveillance. Its use should be reserved for severe and early forms of pre-eclampsia. ${ }^{[11]}$ Several studies have used the following protocol: an attack dose of $4 \mathrm{~g}$ over 20 to 30 minutes and a maintenance dose of $1 \mathrm{~g} / \mathrm{h} \cdot{ }^{[1,9,12,13,14,15]} \mathrm{In}$ case of caesarean section, the infusion was started at least one hour before. She was pursued throughout the intervention and in intensive care. Side effects are present in $24 \%$ of cases when using $\mathrm{MgSO} 4$ versus $5 \%$ in case of placebo. They are represented in $20 \%$ of the cases by a flush. Other reported side effects are nausea and vomiting, muscle weakness, low blood pressure, dizziness and drowsiness, confusional syndrome and headache. Injection site pain and reactions are also more frequent when using $\mathrm{MgSO} 4$ compared to placebo, especially when used intramuscularly rather than intravenously. Toxicity, defined by the abolition of osteotendinous reflexes or respiratory depression, was observed in $1 \%$ of cases with $\mathrm{MgSO} 4$ versus $0.5 \%$ with placebo. The risk of respiratory disturbance or depression was higher in the $\mathrm{MgSO} 4$ group. ${ }^{[13]}$ On the other hand, in case of overdose or renal failure, more serious side effects may occur. Osteotendinous reflexes are abolished when serum magnesium sulfate levels exceed 9 to $13 \mathrm{mg}$ / dl. Respiratory depression occurs at serum levels above $14 \mathrm{mg}$ / dl. These overdoses are most often the result of errors in dosages or infusion rates. ${ }^{[16]}$ but sometimes they are related to the sensitivity of the patient to the product. In these cases, the antidote to be administered is calcium gluconate intravenously at a dosage of $1 \mathrm{~g}$ / h. ${ }^{[9,15]}$ It is classically recommended not to associate magnesium sulphate with calcium channel blockers because of a potentially increased risk of cardiovascular arrest. ${ }^{[16]}$ These recommendations are based on a few clinical cases reported. But this risk does not seem to be found in large randomized trials. In practice, the combination of the two molecules is not contraindicated. Hypocalcemia is the main biological side effect but coagulation disorders have also been described. Magnesemia, which is often not available in our laboratories in developing countries, has no place in therapeutic surveillance, except perhaps in rare cases where renal function and diuresis are impaired. However, it is recommended to monitor the patient clinically for complications. The modalities of use of magnesium sulfate are currently well codified by expert recommendations published in 2009..$^{[9,14,15]}$ For the prevention of eclampsia, most authors associate a loading dose of $4 \mathrm{~g}$ intravenously administered in 15 to 20 minutes followed by a maintenance infusion of $1 \mathrm{~g} / \mathrm{h}$ for 24 hours. ${ }^{[9,14,15]}$ Infusion rates should be controlled by a self-propelled syringe. The duration of treatment, whether started before or after delivery, is not agreed 


\section{International Journal of Innovative Research in Medical Science (IJIRMS) Volume 03 Issue 09 Sept. 2018, ISSN: 2455-8737, Imp. Factor - 4.102 \\ Available online at $-\underline{w w w . i j i r m s . i n}$}

upon. In most randomized trials, treatment is continued for 24 hours. ${ }^{[17,18,19]}$ Two recent studies have suggested the possibility of stopping the perfusion as soon as the functional signs disappear, the control of the blood pressure and the onset of the polyuric crisis (diuresis of more than $100 \mathrm{ml} / \mathrm{h}$ for at least 2 hours). ${ }^{[20,21]}$ Monitoring of the patient throughout the course of treatment with magnesium sulfate should be continuous, monitored under scope, and monitoring of $\mathrm{SpO} 2$ taking into account the risk of respiratory depression. It must be supplemented by the hourly monitoring of osteotendinous reflexes, because the first sign of overdose is their abolition (which justifies stopping the infusion). The determination of magnesium is indicated in cases of clinical signs of overdose but should not delay the management. The antidote is calcium gluconate (two bulbs) and must be available at all times.

\section{Conclusion}

The treatment of eclampsia is nowadays well codified. However, the side effects related to magnesium sulfate are rare and sometimes can be confusing. The rigorous monitoring of patients in intensive care can sometimes detect them. The management must be fast with the use of calcium.

\section{Conflict of Interest}

Authors declare no conflict of interest.

\section{Authors' Contribution}

All the authors have contributed to conduct of this work. All the authors declare that the have also read and approved the final version of this manuscript.

\section{Bibliography}

[1] S. Mezane, M. Achnani, M. Ziyadi, A. Babahabib, R. Hafidi, D. Moussaoui, M. Dehayni. Intoxication with magnesium sulfate in the treatment of eclampsia A propos of three cases and review of the literature. Global Journal of Biology, Agriculture and Health Sciences 2014 ; 3(1): 309-313.

[2] French Society of Anesthesia and Intensive Care Medecine, French national college of obstetricians and gynecologists, French society of perinatal medicine, French society of neonatology. Multidisciplinary management of severe pre-eclampsia. Ann Fr Anesth Reanim 2009 ; 28 : 275281

[3] ACOG Practice bulletin. Diagnosis and management of preeclampsia and eclampsia. ACOG 2002 ; 99 : 159-166

[4] E. Azria, V. Tsatsaris, F. Goffinet, G. Kayem, A. Mignon, D. Cabrol. Magnesium sulfate in obstetrics: current data. Journal de Gynécologie Obstétrique et Biologie de la Reproduction 2004 ; 33(6) : 510-517

[5] Beye M, Diouf E, Kane O, Sall BK, 2003. Intensive care management of 28 patients with severe eclampsia in a tropical African setting. Ann Fr Anesth Reanim. 2003 ; 22: 25-29.

[6] Moujahid H. Management of severe preeclampsia and eclapsia in surgical reanimation. National catalogue of master's and doctoral thesis. Medical doctoral thesis.
Faculty of Fes/Maroc. 2007. Thesis $N^{\circ}$ 024/07. Google Scholar.

[7] Cisse CT, Faye Dieme ME, Ngabo D, Mbaye M, Diagne, PM, Moreau JC. Therapeutics indications and prognosis of eclampsia at Dakar university teaching hospital. J Gynecol Obstet Biol Reprod (Paris) 2003; 32: 239-245.

[8] Belfort MA, Anthony J, Kirshon B. Respiratory function in severe gestational proteinuric hypertension: the effects of rapid volume expansion and subsequent vasodilatation with verapamil. Br J Obstet Gynecol 1991; 98: 964-972.

[9] Chan MT, Boet R, Ng SC, Poon WS, Gin T. Magnesium sulfate for brain protection during temporary cerebral artery occlusion. Acta Neurochir Suppl 2005; 95:107111.

[10] Richards A, Stather-Dunn L, Moodley J. Cardiopulmonary arrest after the administration of magnesium sulfate. S Afr Med J 1985; 67:145.

[11] ACOG practice bulletin. Diagnosis and management of preeclampsia and eclampsia. Obstet Gynecol 2002; 99: 159-167.

[12] Sibai BM. Magnesium sulfate is the ideal anticonvulsant in prééclampsie-eclampsia. Am J Obstet Gynecol 1990;162:1141-1145.

[13] Kayem G, Mandelbrot L, Haddad B. Use of magnesium sulfate in obstetrics. Gynécologie Obstétrique \& Fertilité, 2012 ; 40(10) : 605-613.

[14] Prise en charge multidisciplinaire des formes graves de prééclampsie. Recommandations formalisées d'experts communes J Gynécol Obstet Biol Reprod 2009; 38:351357.

[15] Cagnat, GO. Treatment by magnesium sulfate. 2017. Google scholar

[16] Duley L, Gulmezoglu AM, HendersonSmart DJ, Chou D. Magnesium sulphate and other anticonvulsants for women with preeclampsia. Cochrane database of systematic reviews 2010; 11:CD000025. Google scholar

[17] The Magpie Trial Collaborative Group. Do women with pre-eclampsia and their babies, benefit from magnesium sulphate? The Magpie Trial: A randomised placebocontrolled trial. Lancet 2002; 359:1877-1890.

[18] Coetzee EJ, Dommisse J, Anthony JA. Randomised controlled trial of intravenous magnesium sulphate versus placebo in the management of women with preeclampsia. Br J Obstet Gynaecol 1998;105(3) : 300-303.

[19] Belfort MA, Anthony J, Saade GR, Allen Jr JC. A comparison of magnesium sulfate and nimodipine for the prevention of eclampsia. N Engl J Med 2003;348:304311.

[20] Sibai BM. Diagnosis, prevention, and management of eclampsia. Obstet Gynecol 2005;105(2) : 402-410.

[21] Isler CM, Barrilleaux PS, Rinehart BK, Magann EF, Martin Jr JN.Postpartum seizure prophylaxis: Using maternal clinical parameters toguide therapy. Obstet Gynecol 2003;101(1) : 66-69. 